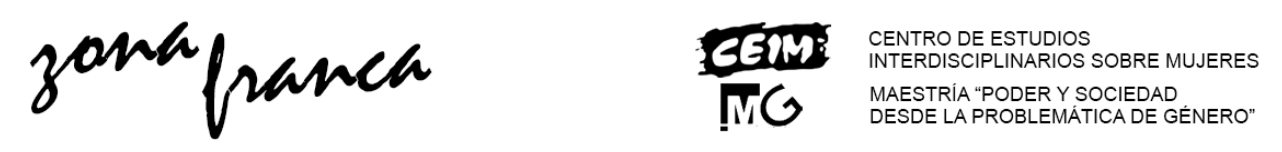

\title{
Revolución en dos ruedas: Los dolores y placeres de mujeres montando bicicleta durante el Período Especial
}

Jennifer Ruth Hosek *

\section{Resumen}

Este artículo investiga la cultura ciclística en Cuba durante el período especial desde una perspectiva que enfatiza género y sexualidad. La ingeniosa y radical respuesta de Cuba al fin de las entregas soviéticas de petróleo subsidiado notablemente combustibles y fertilizantes - incluyó un rápido, masivo e internacionalmente elogiado despliegue del transporte en bicicleta. Sostengo que, si bien el ciclismo de adulto en La Habana seguía siendo una actividad más asociada con los hombres y la masculinidad, su uso por la mayoría de la población promovió una identificación más amplia con esta práctica, sobre todo entre las mujeres. Además, aunque la bicicleta devino metonimia del sufrimiento durante el período especial, también facilitó un acercamiento no normativo a la sensualización y sexualización del esfuerzo físico tanto de la mujer como del hombre.

Palabras clave: ciclismo; Cuba; emancipación; mobilidad; mujeres

\section{Revolution on Two Wheels: Pains and (Liberatory) Pleasures of (Women) Bicycling in the Special Period}

\begin{abstract}
This contribution investigates bicycling culture in the Special Period with a focus on gender and sexuality. Cuba's ingenious, radical response to the end of Soviet deliveries of subsidized petroleum products-notably fuels and fertilizersincluded rapid, massive, and internationally- celebrated deployment of bicycle transportation. I argue that while adult bicycling in Havana had traditionally been an activity associated with men and masculinity, its widespread uptake by the urban populace furthered a broader-based identification with the practice, notably among women. Further, although bicycling came to metonymize the suffering of the Special

\footnotetext{
*Título original: "Revolution on Two Wheels: Pains and Pleasures of Bicycling in the Special Period". En Cuban Studies 2021. no. 50: 251-276. Traducción de Víctor Fowler Calzada. Escritor cubano. Especialista en Industrias culturales, MINCULT.
}

Revista Zona Franca- Centro de estudios interdisciplinario sobre las mujeres (CEIM)- Maestría poder y sociedad desde la problemática de género (MG), Rosario, Argentina. ISSN, 2545-6504 http://zonafranca.unr.edu.ar/index.php/ZonaFranca| Número 29 (2021).


Period, it also facilitated a non-normative sensualisation and sexualization of (mutual) physical exertion for women as well as men.

Keywords: bicycling; Cuba; emancipation; mobility; women

\section{Introducción}

En Sergio y Serguei (Ernesto Daranas, 2016) sale la clarísima imagen del Período Especial: el tipo todo flaco, con un niño alante y la madre atrás en la parrilla con otro. En ese tiempo, [había que] dar bicicleta de aquí a no sé dónde, sin estar bien alimentado.

Esa imagen no debe ser creada de ahora, debe ser de antes, porque la expresión está muy bien creada . . . Era la única manera de llegar a los lugares. $\mathrm{SN}$ - mujer, profesional, raza blanca, heterosexual, 39 [entre 11-16 durante el Período Especial].

También están las personas que bajaron mucho de peso. En el Período Especial había mucha gente como yo estoy ahora [muy delgada]. Y mucha gente que no se sentía bien, de salud ni de ánimo. Y aunque no he hablado mucho de esto, creo que era por la misma bicicleta. O sea, que la bicicleta era la solución a muchos problemas, pero era un problema en sí mismo ¿Cómo te explico? Era complicado el asunto.

BR - mujer, profesional, raza blanca, heterosexual, 54 [26-30 durante el Período Especial].

A más de sesenta años tras su nacimiento, los impactos de la Revolución Cubana continúan de formas sostenidas y múltiples. Para muchos dentro del Norte Global, el despliegue en Cuba del transporte por bicicletas durante el Período Especial es una continuación de los triunfos de la Revolución. Con la ruptura de la Union Soviética en los noventas, las relaciones comerciales de Cuba con ese país y el resto de las naciones pertenecientes al Consejo de Ayuda Mutua Económica se

Revista Zona Franca- Centro de estudios interdisciplinario sobre las mujeres (CEIM)- Maestría poder y sociedad desde la problemática de género (MG), Rosario, Argentina. ISSN, 2545-6504 http://zonafranca.unr.edu.ar/index.php/ZonaFranca| Número 29 (2021). 
vieron disueltas de modo repentino. Terminó entonces la entrega sostenida de bienes, incluyendo el subsidio de productos derivados del petróleo que se usaban en la generación de energía, la industria agropecuaria y en la movilidad impulsada por motores de combustión. El Gobierno cubano concibe una respuesta a la situación dirigida a sostener la estabilidad social y política, a cubrir las necesidades básicas y mantener alguna versión de la vida normal para la población. Gracias a un trato comercial de emergencia con su aliado China, Cuba comenzó rápidamente a importar y distribuir robustas bicicletas de alta calidad -tanto de carga como de transporte personal- para apoyar la movilidad en las ciudades y zonas rurales (Petschek and Churchhill, 1996; Xianglin, 2014). También se crearon los jardines orgánicos a pequeña escala para aumentar la producción de alimentos en ausencia de una petro-agricultura. En el imaginario popular de los aliados internacionales, especialmente en el de aquellos con perfil de izquierda, las bicicletas y los jardines orgánicos -más que nada en la capital del país- encarnaban el continuado espíritu y práctica revolucionarios de Cuba ante circunstancias difíciles y contra dificultades enormes luego del final de la Guerra Fría (Scarpaci and Hall, 1995; Rios, 1993).

\section{Montar bicicleta como dolor y placer.}

Esta contribución da cuenta de lo que significaba montar bicicleta en la Habana durante los momentos más austeros del Período Especial, aproximadamente 19901995, particularmente en su relación con el género y la sexualidad. Mis referencias sobre el Período Especial se limitan a ese lapso, aunque las influencias que examino pueden ser extendidas más allá. Al decir "tiempos más austeros", me refiero al ciclo que empieza el 30 de diciembre de 1990, cuando Fidel Castro anunció la llegada de un Período Especial en Tiempos de Paz, y termina en 1996 cuando "las reformas del mercado comienzan a dar resultados" y más productos comenzaron a estar disponibles. Las bicicletas fueron estratégica y logísticamente esenciales para la supervivencia nacional durante este tiempo. Ariana HernándezReguant, académica especializada en temas cubanos, menciona el reporte del periódico Granma acerca de un evento que tuvo lugar a principios de abril de 1991,

Revista Zona Franca- Centro de estudios interdisciplinario sobre las mujeres (CEIM)- Maestría poder y sociedad desde la problemática de género (MG), Rosario, Argentina. ISSN, 2545-6504 http://zonafranca.unr.edu.ar/index.php/ZonaFranca| Número 29 (2021). 
en la Plaza de la Revolución, para conmemorar el aniversario de la Unión de Jóvenes Comunistas (UJC) y durante el cual Fidel Castro y el presidente de la UCJ, Roberto Robaina, pidieron a la juventud mantener su lealtad durante los venideros tiempos de dificultad. Hernández-Reguant escribe:

\begin{abstract}
"El periódico también incluyó un breve comentario sobre lo diferente que fue la atmósfera del evento. "Dos cosas nuevas sucedieron", observó la periodista... Lo primero fue "la proliferación de las bicicletas", las que parecían inundar las calles adyacentes durante la concentración. La segunda fue "la resurrección" de un lema del Ché Guevara: 'Hasta la Victoria Siempre', el que Robaina reintrodujo (4-5)."
\end{abstract}

El académico chino Mao Xianglin, investigador sobre temas cubanos; igualmente describe una formación de cerca de cien mil ciclistas en el desfile del Primero de Mayo de 1993, al igual que la aparición de la bicicleta en varios eventos públicos e internacionales (2019).

Según propongo, muy especialmente durante el austero Período Especial, la adopción generalizada de la bicicleta por la mayoría de la población que era físicamente capaz de hacerlo fomentó una identificación amplia y el disfrute de este medio de transporte entre algunos practicantes, notablemente mujeres. Por supuesto, cada miembro de la población experimentó y experimenta el acto de montar bicicleta de forma diferente. Hasta la llegada del Período Especial, el uso de bicicletas entre adultos se relacionaba sobre todo con hombres y con la masculinidad, en especial entre los profesionales de zonas urbanas, que lo practicaban de forma recreativa (Scarpaci and Hall, 242). Siendo muy a menudo el único medio de transporte durante el Período Especial, montar bicicleta se volvió algo necesario, apoyado y, con frecuencia, ordenado por el gobierno. Al ser esta una acción que se emprendía comúnmente en condiciones muy adversas, el dolor derivado de la misma no se debe pasar por alto; de hecho, montar bicicleta se vuelve una metáfora del sufrimiento del Período Especial. Aún así, montar bicicleta también

Revista Zona Franca- Centro de estudios interdisciplinario sobre las mujeres (CEIM)- Maestría poder y sociedad desde la problemática de género (MG), Rosario, Argentina. ISSN, 2545-6504 http://zonafranca.unr.edu.ar/index.php/ZonaFranca| Número 29 (2021). 
facilitó una sensualización/sexualización no normativa del esfuerzo físico tanto en hombres como mujeres. De hecho, incluso durante estos años tan dificiles, los beneficios para la salud, pragmáticos, para el medioambiente y aspectos sociales del uso de la bicicleta eran reconocidos; estos aspectos se encuentran cada vez más articulados hoy día, en especial para los habaneros que montan bicicleta por elección.

\section{Métodos y Fuentes}

Para respaldar mi argumento, examino una variedad de textos sobre la base de un enfoque de estudios culturales que comprende la cultura de manera amplia y como algo ampliamente expresado (Bennett, Grossberg and Morris, 2005; Turner, 2003). Estos textos son quince entrevistas cualitativas realizadas en el año 2018 a cubanos residentes en La Habana, conversaciones informales y entrevistas formales que he sostenido con una gran cantidad de interlocutores cubanos -de una amplia gama de posicionalidades- a lo largo de los últimos diez años; textos cubanos sobre montar bicicleta publicados durante el Período Especial y dos largometrajes cubanos -Madagascar (1994) y Nada (2001)- en los cuales la bicicleta tiene un importante papel. Aunque ambos filmes tratan sobre estrategias de supervivencia en el Período Especial, Madagascar presenta el acto como una cuestión de sufrimiento, mientras que Nada lo muestra más como algo placentero.

Las entrevistas cualitativas fueron hechas entre Marzo y Octubre del 2018 por la investigadora cubana Camila Cabrera. El trabajo de Cabrera incluye proyectos en Casa de las Américas, donde ella se especializa en Estudios Culturales Latino Americanos desde los años noventa hasta el presente. Para estas entrevistas, Cabrera le preguntó a distintos habaneros, en entrevistas semi-estructuradas de final abierto, acerca de qué era lo que ellos consideraban que había sido una experiencia vivida como un cambio radical en la Habana de inicios de los noventa del pasado siglo. Ella buscó cinco hombres y diez mujeres para lograr una pequeña muestra de la población urbana, quienes habían experimentado el austero Período

Revista Zona Franca- Centro de estudios interdisciplinario sobre las mujeres (CEIM)- Maestría poder y sociedad desde la problemática de género (MG), Rosario, Argentina. ISSN, 2545-6504 http://zonafranca.unr.edu.ar/index.php/ZonaFranca| Número 29 (2021). 
Especial en su juventud o mediana edad (las edades van de los 10 años a los cuarenta); teniendo en cuenta las intersecciones de racialización, orientación sexual, educación y ocupación. Dado que Cabrera tenía un interés particular en las experiencias femeninas, decidió entrevistar más mujeres que hombres. El conjunto real de los entrevistados sobre-representa a gente que son relativamente privilegiadas. La mayoría tiene un título universitario o de técnico medio y trabajan como profesionales o cuentapropistas (trabajadores por cuenta propia o dueños de pequeños negocios). La mayoría vive en la zona central de la capital —en La Habana Vieja, Centro Habana y El Vedado. Estos espacios pertenecen a la clase media cubana, lo cual en la definición de Cabrera significa que tienen algo más que una educación de bachillerato y suficiente acceso a la moneda dura como para cubrir sus necesidades y que después les quede algo para pequeños lujos (Espina, 2008; Bastian, 2018). La constitución de facto del grupo, a pesar de las intenciones iniciales de Cabrera, en parte es debido a la técnica de "bola de nieve" que ella empleó para seleccionar a los entrevistados y por la naturaleza voluntaria del ejercicio. Esos interlocutores potenciales -con mayor grado académico y con trabajos más profesionales- estaban más dispuestos a participar y a sostener opiniones sobre montar bicicletas que las que deseaban airear. En muchos casos, ellos estaban particularmente interesados en el tema debido a sus propias experiencias montando bicicleta. A pesar de ser una muestra no muy representativa, tanto Cabrera como yo encontramos que sus resultados ofrecen perspectivas significativas en el tema del uso de la bicicleta, en especial entre los habitantes privilegiados de las áreas centrales de La Habana de los últimos cuarenta años. Los entrevistados estaban comprometidos y bien informados sobre la materia en cuestión y los temas y tópicos que mencionaban se repetían. Haría falta realizar un trabajo futuro con otras partes de de la población, como sectores más pobres que vivan en zonas menos centrales y aventajadas - o ciudades más pequeñas/ zonas rurales - para enriquecer el trabajo realizado y completar el conocimiento que se tiene acerca del uso de la bicicleta en Cuba.

Revista Zona Franca- Centro de estudios interdisciplinario sobre las mujeres (CEIM)- Maestría poder y sociedad desde la problemática de género (MG), Rosario, Argentina. ISSN, 2545-6504 http://zonafranca.unr.edu.ar/index.php/ZonaFranca| Número 29 (2021). 


\section{Trasfondo: En motores y pedales}

Insertar la bicicleta en el transporte diario habanero de inicios de los 90's resultó equivalente a forzar el poder del pedaleo en el interior de una cultura del transporte motorizado que largo tiempo había privilegiado el automóvil (Gott 2005, 165; Pérez, 2001). El automóvil, por lo común, es considerado una máquina de privilegio masculino,10 (Böhm, Jones, Land y Paterson, 2007) "cada cubano sueña con tener auto" un viejo mantra popular en la isla (Santos y Hosek, 2016).' En la década de los 50's del pasado siglo, la clase media estadounidense se había convertido en poseedora de automóviles (Weiss, 2003), y la cercana relación de la Habana con los Estados Unidos significaba que los autos eran importados con liberalidad, cosa esta que marcaba el paisaje de la transportación, representando a la vez- una imagen de neocolonialismo y "buena vida norteamericana (Narotzky, 2002)." Previo a esta proliferación de autos, muchos cubanos privilegiados poseían bicicletas, por lo general para recreación y práctica de deporte. Había clubs de usuarios de estas, y publicaciones como la titulada El Ciclista aparecían en la Isla ya desde los años 90's en el siglo XIX. En Cuba, lo mismo que en Estados Unidos y muchos otros países por la fecha, la bicicleta era un objeto propio del ámbito masculino, por norma general en manos de varones blancos. Las mujeres que utilizaban el vehículo eran vistas como transgresoras de normas." Ellas estaban en buena compañía junto a mujeres ciclistas del mundo entero (Muellner, 2002).

En la imaginación popular, la Revolución cubana puede ser asociada a los automóviles estadounidenses -por ejemplo con imágenes de dirigentes frenando convertibles de lujo, quizás requisados, al llegar a los cuarteles provisionales del

I Un lector recuerda agrega la canción "un carro, una casa, una buena mujer," la cual es también citada en el documental Balseros (Carlos Bosch, 2002).

"Revisión de los periódicos y revistas existentes en la Biblioteca Nacional José Martí bajo la palabra clave "bicicleta" (consultados en abril-mayo 2015).

Revista Zona Franca- Centro de estudios interdisciplinario sobre las mujeres (CEIM)- Maestría poder y sociedad desde la problemática de género (MG), Rosario, Argentina. ISSN, 2545-6504 http://zonafranca.unr.edu.ar/index.php/ZonaFrancal Número 29 (2021). 
Gobierno Revolucionario en el Hotel Habana Libre III a pesar de que las nuevas autoridades promovieron el uso de bicicletas (y de ómnibus) por razones de mobilidad, equidad, economía y salud (Bobes, 2011). Dado que tanto los autos nuevos como las piezas de respuesto procedentes de los Estados Unidos no estarían disponibles más, no hay duda de que el embargo contribuyó a esta decisión (Sartre, 1961; Cluster y Hernández, 2016). En verdad, durante los primeros años de la Revolución, sus líderes pudieron haber contemplado la bicicleta como una herramienta fundamental para la joven nación (Hosek, 2018). A inicios de los 1960s, el entonces Ministro de Industrias, Ernesto "Ché" Guevara, realizaba largos viajes por Latinoamérica y Europa con objetivos que incluían la concreción de acuerdos para la construcción de fábricas. Dos de las primeras fueron la fábrica de lápices "Mitico Fernández" en Batabanó y la de bicicletas, "Heriberto Mederos", en Caibarién.

No sorprende la necesidad de una fábrica de lápices. La Campaña de Alfabetización cubana ha sido bien documentada y fue bien recibida, incluso entre los detractores de la Revolución Cubana, ya que -por norma general- la alfabetización se consideraba como un beneficio, si no un derecho e incluso como algo bueno para los negocios. La Campaña convocaba a educar para todo tipo de trabajo, en esta nueva nación de la cual muchas personas educadas habían partido, atravesaba todas las líneas de diferencia para reunir a la ciudadanía alrededor de un empeño común y enseñaba los principios de la Revolución Cubana. Este programa de alfabetización es ampliamente reconocido como un aspecto central del proyecto cubano (Lewis, Lewis y Rigdon, 2019)

El reconocimiento a la bicicleta es mucho menos conocido, aunque la decisión gubernamental de priorizar la fabricación de bicicletas pareciera hablar de su importancia estratégica en esos momentos iniciales. El Ché Guevara pronunció ante

III Incluso la socialista Alemania del Este estrenó la ficción basada en hechos reales Und deine Liebe auch. (Hosek, 2012: 108-119).

Revista Zona Franca- Centro de estudios interdisciplinario sobre las mujeres (CEIM)- Maestría poder y sociedad desde la problemática de género (MG), Rosario, Argentina. ISSN, 2545-6504 http://zonafranca.unr.edu.ar/index.php/ZonaFrancal Número 29 (2021). 
los trabajadores el discurso propio de una inauguración como esta el 19 de Julio de 1964. Habló de la importancia de producir eficientemente productos de calidad para el mercado de consumidores domésticos y acerca de probar al mundo que un país socialista nuevo, nacido de una lucha armada, podía tener éxito y crecer, en especial mientras confrontaba a los Estados Unidos. IV Además de ello, y ya más especificamente, enfatizó la importancia de esas robustas bicicletas, que parecieran estar hechas más para ser empleadas para cosas prácticas antes que para un uso recreacional:

"La fábrica va a producir por ahora 20.000 bicicletas. Este año producirá solamente 5.000. . . Ya hay algunas que ustedes podrán ver. Están bastante bonitas. No sé si se desarmarán después que uno ande un poco, pero parece que están fuertes. Ustedes tendrán que decir cómo es el producto. Esta es una fábrica sencilla, pequeña, tendrá un poco más de cien trabajadores, pero evidentemente contribuye a solucionar un problema importante de Cuba (Guevara, 1964)."

Otros sistemas de gobierno han colocado la bicicleta en primer plano para facilitar el logro de intereses nacionales (Guroff, 2016). Con frecuencia la bicicleta es vista como un apoyo de la movilidad igualitaria y por extensión de la democracia (Vivanco, 2013; Blue, 2016). Esta investigación no da respuesta a la cuestión de hasta que punto el gobierno cubano joven intentó mejorar la calidad de vida del pueblo cubano ofreciendo apoyo a la bicicleta. Mi investigación hasta la fecha sugiere que el énfasis de Cuba en el uso de la bicicleta en los ambientes urbanos declinó a medida que las relaciones con la Unión Soviética se fortalecían. La confianza en el progreso tecnológico modernista, así como las inversiones al efecto,

IV Construir bicicletas requirió de convenios internacionales. Checoeslovaquia proveyó muchas piezas de bicicletas. (Guevara, 1964; Zuloaga Martínez, 2013). En los 1990's China suministró piezas (Xianglin, 2019).

Revista Zona Franca- Centro de estudios interdisciplinario sobre las mujeres (CEIM)- Maestría poder y sociedad desde la problemática de género (MG), Rosario, Argentina. ISSN, 2545-6504 http://zonafranca.unr.edu.ar/index.php/ZonaFrancal Número 29 (2021). 
aumentaron con la Guerra Fría y la carrera espacial; al mismo tiempo, automoviles y ómnibus, en particular de los llamados "países del Este", llegaron a la populosa Habana.

La cultura cubana de la bicicleta no volvió a florecer nuevamente hasta los años 1990s del pasado siglo. Durante este tiempo de escasez de todo, incluyendo el papel, algunos medios de comunicación remarcaban, en el imaginario popular, los valores de la bicicleta. En 1995, la Editora Política publicó Ché Deportista (del autor William Gálvez), volumen que -además de incluir fotos de un Guevara joven haciendo un recorrido en bicicleta-, mostraba en la portada la foto de uno de estos vehículos. El delgado volumen describe el viaje de varios días realizado por Guevara en el mismo tono reverente de las narrativas ulteriores que relatan su mucho más famoso viaje en motocicleta. Che Deportista no destaca la bicicleta más que otros deportes de resistencia, aunque su tratamiento sin dudas que aumentó el prestigio de la bicicleta como una actividad física revolucionaria. A lo largo de los 1990s, los dibujos de René de la Nuez alegraron los periódicos cubanos y más tarde, en el 2003, fueron compilados y publicados por Ediciones UNION en un voumen titulado CubaBici. Numerosos artículos y noticias también tenían la bicicleta como tema. Había consejos prácticos dedicados a la seguridad y reparación del vehículo, reportes a propósito de accidentes y sistemas de tráfico, y artículos a propósito de beneficios de salud, personales, sociales, y nacionales. ${ }^{\vee}$ La televisión también puso en las pantallas varios spots promocionales y educacionales, pocos de los cuales sobreviven todavía hoy. EI MINFAR (Ministerio de las Fuerzas Armadas) encargó al director de audiovisuales Luis Deulofeu, la realización de un cortometraje titulado Forever (1994), cuyo nombre hace referencia a la marca de uno de los modelos de bicicleta importados desde China. Junto a ello, en diversas

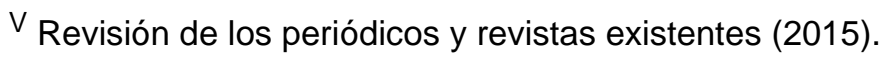


películas de la época se aprecia la centralidad que este medio de transporte había ganado en la vida cubana.

Una de las pocas películas realizadas en los 1990s, Madagascar de Fernando Pérez, articula liricamente el presente y futuro potencial de la Habana. Pérez habla acerca de expresar las "laceraciones espirituales" de los habaneros en esta obra cuya duración hubo de ser recortada debido a la escasez de recursos (Pérez, 2016; Pérez, 2011). Su narrativa hiperreal y surreal explora las subjetividades de una madre y su hija para ofrecer una extensa visión compartida de la subjetividad urbana. Las impactantes imágenes de bicicletas -que dibujan tanto el problema de la imposibilidad de vida en el Período Especial como las soluciones domésticas provisionales frente a él- abren y cierran el relato.

En la narrativa, Laura, profesora de Física, está completamente inmersa en el manejo de los desafíos cotidianos mientras que su hija, Laurita, explora las vías de disociarse de todo ello. Laura no puede distinguir el sueño de los momentos en los que se encuentra despierta, ya que vive y sueña las mismas tribulaciones. Entre tanto, Laurita anuncia sus planes de ir a Madagascar, un espacio interior de sueños en el cual nunca ha estado (cp. Ruffinelli, 2005). Laura está tan sumergida en la realidad que no puede imaginar alguna alternativa, mientras que Laurita está tan desconectada que no puede ayudar a crearlas. De ambas vidas, ninguna es defendible para una supervivencia individual o societal.

Las escenas con bicicletas expresan y responden a estas circunstancias. La absorbente secuencia inicial muestra hombres, desde la cintura hacia arriba, moviéndose en cámara lenta en un desplazamiento surreal, de un lado al otro, en dirección a la cámara. Un tenue foco, evocativo de calor, humedad, sudor y polvo, el leve alargamiento de lo que un suave zoom de alejamiento revela que son personas montando bicicletas, y la banda sonora que combina jadeo, ruidos de tráfico urbano, y crescendos melódicos remarcan liricamente el esfuerzo y la resignada determinación en cada uno de los rostros de los viajeros y en sus

Revista Zona Franca- Centro de estudios interdisciplinario sobre las mujeres (CEIM)- Maestría poder y sociedad desde la problemática de género (MG), Rosario, Argentina. ISSN, 2545-6504 http://zonafranca.unr.edu.ar/index.php/ZonaFranca| Número 29 (2021). 
movimientos. Con la excepción de una adolescente, todos son hombres dirigiéndose al trabajo, la mayoría vistiendo atuendo de oficina. Cuando el cuadro se abre más, la locación es reconocible como el Puente de Hierro, paso que enlaza Ios lujosos vecindarios El Vedado y Miramar. Durante el Período Especial este punto fue destinado para el cruce exclusivo de peatones y bicicletas y permanece como un emblemático lugar de cruce para vehículos no-motorizados. El retrato que en esta secuencia de apertura se hace de trabajadores masculinos, y la intensidad del esfuerzo que realizan, sugiere una situación insostenible; a la misma vez, el hecho de que sus movimientos sean desplegados en coordinación, y no en desacuerdo, sugiere los comienzos de un camino a seguir. La imagen siguiente presenta a un densa y heterogénea multitud de ciclistas que marchan a pie, llevando las bicicletas de la mano. La cámara va distanciándose y elevandose para terminar revelando una larga columna humana que, poco a poco, avanza con resignación y decisión a través del puente, hacinándose adentro, debajo y después del cuadro; en la medida en la que el foco frontal se mantiene dirigido a estos peatones, la cámara ignora sus destinos potenciales.

La impactante penúltima escena que muestra a Laurita, Laura, y todo un grupo de cubanos con bicicletas sugiere sufrimiento y, con mayor claridad que antes, un camino a seguir. Laurita justo ha regresado a vivir con su madre y abuela -las tres generaciones a que nos remitía Lucía (1968), la icónica alegoría de la nación elaborada por director Humberto Solás (Chanan, 2017). En la toma de apertura, lateral-frontal a media distancia, la pareja de protagonistas llevan bicicletas, caminando una al lado de la otra y hablando, rodeadas por una heterogénea masa humana que también conduce sus transportes a través del túnel de la bahía. A medida que la discusión entre ellas continúa, la cámara gira y hace un paneo hacia una posición estática, en un ángulo alto tomado desde la parte trasera de la continua, interminable columna de personas que sigue andando a través del túnel. A diferencia de la escena descrita previamente -en la cual la filmación omite, incluso

Revista Zona Franca- Centro de estudios interdisciplinario sobre las mujeres (CEIM)- Maestría poder y sociedad desde la problemática de género (MG), Rosario, Argentina. ISSN, 2545-6504 http://zonafranca.unr.edu.ar/index.php/ZonaFranca| Número 29 (2021). 
bloquea la trayectoria presumible de los caminantes-, aquí el cambio en el encuadre ofrece un vislumbre del destino.

Tan poco común e incluso sombrío como es esta escena de gente caminando un espacio hecho para automóviles, deja abierta una trayectoria resueltamente optimista. Para empezar, nos deja la referencia a una inusual y efectiva solución a la falta de un sistema de transportación para cruzar de un lado a otro de la bahía. En 1992-1993, una de las entradas del túnel fue cerrada al tráfico automotor y abierta para tráfico de pie y de bicicleta. Poco después esto, un bus -destinado para llevar a los ciclistas y sus bicicletas- empezó a facilitar la movilidad a través del túnel. Mientras que la caminata a lo largo del túnel resultaba poco agradable —la escena retrata la travesía como algo claustrofóbico- la decisión de planificación urbana exitosamente implementada permitió que la gente alcanzara los destinos deseados. Luego de esto, en particular al compararlo con las escenas anteriores de bicicleteros y caminadores, este grupo heterogéneo sugiere, en sí mismo, esperanza. Los que van a pie enseñan gestos simples y comunicativas- con frecuencia tocándose 0 hablando uno con otro; se mueven siguiendo un propósito, pero los cuerpos lucen relajados y se brindan mutuamente el necesario espacio personal. Esta escena es diferente del penoso esfuerzo de los bicicleteros masculinos individuales o del apretujado grupo que abre la película. A diferencia de aquellas escenas previas, en las que el posicionamiento de la cámara excluye cualquier vislumbre de un destino, aquí la cámara rastrea el paso continuo de quienes se desplazan en busca de la salida del túnel que, aunque oscura y mal definida, es encuadrada. Además, el diálogo de Laura y Laurita articula una solución dialéctica a través de una síntesis compartida de utopía y realidad. Madre e hija han intercambiado perspectivas: Laura está planeando ahora un viaje a Madagascar y Laurita -que ha reiniciado su vida escolar- tiene sueños que son iguales que su vida diaria. Así, entre ambas y a lo largo de la historia, estas representantes de dos de las generaciones -en una familia fuertemente unida que opera como metonimia de la sociedad cubana- establecen 
una trayectoria en la cual se funden la realidad y las alternativas, imaginadas y deseadas, mientras se mueven juntas hacia adelante.

La estática toma final de Madagascar -desde abajo hacia encima- subraya esta trayectoria. El encuadre muestra un grupo de chimeneas, en apariencia inactivas, detrás de un conjunto de elevadas líneas de ferrocarril a cuyo largo un tren se mueve con lentitud. El realizador Pérez explica que la banda sonora -en la que se escucha a la conocida intérprete cubana Omara Portuondo, ejecutando la popular canción de amor "Quiéreme mucho"- expresa una esperanzada "declaración de verdadero amor" por la ciudad y por el país, una que resultaba comprensible para la mayor cantidad de espectadores domésticos (Kabous, 2009: 6). En la penúltima escena, los residentes con sus bicicletas se mueven de izquierda a derecha, alejándose del encuadre de una cámara móvil que los captura desde lo alto. En esta toma final, el tren se desplaza de derecha a izquierda a lo largo del encuadre de una cámara estática que toma la acción de abajo hacia encima. La yuxtaposición, durante el final de la película, de este par de secuencias, sugiere múltiples posibilidades para el movimiento hacia el futuro mediante los esfuerzos concertados entre todas las partes de la población.

\section{Discusiones sobre el Ciclismo en el austero Período Especial}

Sobre Madagascar, la entrevistadora Camila Cabrera resume los comentarios de un entrevistado de la siguiente manera: "Menciona las escenas de inicio y final de un filme de Fernando Pérez, Madagascar, que hablan mucho de ese período. Muestra cómo se trasladaban las personas, 'prácticamente como en tribus; una imagen muy particular.' Siempre recurre a esa imagen, cuando recuerda esa etapa y sus experiencias en bicicleta" (entrevista con JLBH - hombre, mestizo, heterosexual, 45 [17-22 en el Período Especial], profesional). Para ese entrevistado, la película evoca la sensación de una comunidad de bicicleteros que se mueve en tiempos difíciles. ¿Qué es lo que los entrevistados de Cabrera y mis interlocutores tienen que decir sobre las experiencias de las mujeres en bicicletas?

Revista Zona Franca- Centro de estudios interdisciplinario sobre las mujeres (CEIM)- Maestría poder y sociedad desde la problemática de género (MG), Rosario, Argentina. ISSN, 2545-6504 http://zonafranca.unr.edu.ar/index.php/ZonaFranca| Número 29 (2021). 
Tanto los residentes de La Habana con quienes he hablado como aquellos entrevistados por Cabrera están de acuerdo en que, en la década de 1980, montar bicicletas era visto como algo más acorde a los hombres que a las mujeres. En ese entonces, las bicicletas eran generalmente juguetes para niños, algunas veces un medio recreativo, y otras pocas una manera de transportarse, particularmente para adolescentes masculinos (Suárez, 2019). El hecho de que también fuesen difíciles de obtener es otra muestra de su estatus como objetos de lujo. G, mujer, 61 [33-38 en el Período Especial], heterosexual, graduada universitaria, privilegiada económicamente, mestiza, conferencista - así como muchos otros - afirman que, en la década de 1980, las mujeres pedalistas eran llamadas algunas veces marimacho.

Traducido con frecuencia al inglés como "tomboy," marimacho puede significar también, por lo general de modo peyorativo, mujer que ama a otra mujer. Por lo tanto, el uso de este término no solo etiquetaba a las mujeres ciclistas, sino que también especulaba sobre sus deseos y actividades sexuales. La propia $\mathrm{G}$ ofreció una explicación de por qué - dentro de un contexto normativo cubano - el término marimacho puede ser visto como una consecuencia lógica de montar bicicletas. Esta actividad conlleva el uso de un vestuario práctico - pantalones y zapatos deportivos. Las mujeres que se visten de esta forma son percibidas como menos femeninas. También se percibe que se esfuerzan menos por atraer el interés sexual de los hombres. Para $G$ y otros con quienes he hablado, la ropa y el calzado femeninos, el maquillaje, y los peinados complejos eran vistos en la Cuba de los 80' como marcas de feminidad y heterosexualidad. Simbólicamente hablando, sin estas marcas una hembra era menos mujer. Como en muchas naciones socialistas, las tensiones entre las normas de belleza femenina burguesas, más establecidas, y otros nuevos modelos de apariencia para la mujer, que están menos orientados al consumo, comenzaron justo con el cambio de gobierno. El reciente análisis de María A. Cabrera Arús y Mirta Suquet sobre la Cuba de las décadas de 1960 y 1970 
recuerda como las tensiones y los valores nacionales se expresan frecuentemente en los cuerpos femeninos (2019; cp. Calvo-Peña, 2005).

Además del término marimacho, que especula acerca de las preferencias sexuales de las pedalistas, la sexualidad de las pasajeras era controlada de manera general. De acuerdo con G. y otros, si una mujer viajaba como parrillera - sentada en la parrilla posterior de una bicicleta - se pensaba que potencialmente tendría intereses románticos y/o sexuales en el hombre que fuera pedaleando. Cuando una mujer viajaba entubada - en la barra superior del marco, entre las piernas del pedalista - esto sugería que su relación era íntima. G cuenta una historia graciosa acerca de su propia experiencia como parrillera. En 1990, habiendo ganado una bicicleta en su centro de trabajo por ser una empleada destacada, necesitaba llevarla a casa. No sabía como montar, no obstante, logró que un hombre -en quien sí tenía un interés amoroso- la ayudara y se agarró fuerte a él durante el viaje de regreso.

Hasta aquí he desarrollado el testimonio de G. Muchas de las respuestas de mis interlocutores y los de Cabrera evidencian por igual que las determinaciones sociales acerca de las prácticas sexuales y locomotrices normativamente apropiadas - determinaciones orientadas patriarcalmente y por el género como son -- interpretaron y moldearon el movimiento de mujeres en bicicletas. Tomando como apoyo trabajo hecho en Norteamérica, me atrevo a asegurar que, en este caso, tales lógicas establecieron vigilancia sobre la movilidad femenina cuando mujeres que se embarcaron en prácticas no normadas por el género, como el acto de montar bicicleta, eran juzgadas en el espectro que iba desde la "inadecuación" de su feminidad hasta identificación de una presunta homosexualidad. De manera similar a como, viviendo su orientación sexual, las mujeres que aman a otras mujeres expresan y expanden eso que Helen Lenskyj Ilamó en 1987 "flexibilidad de los roles de género" (382), en el Período Especial de la Cuba revolucionaria, las mujeres montando bicicletas y el hecho de que las mujeres montaran bicicletas expresaron

Revista Zona Franca- Centro de estudios interdisciplinario sobre las mujeres (CEIM)- Maestría poder y sociedad desde la problemática de género (MG), Rosario, Argentina. ISSN, 2545-6504 http://zonafranca.unr.edu.ar/index.php/ZonaFranca| Número 29 (2021). 
y expandieron de diversas maneras la flexibilidad de los roles de género dentro del patriarcado.

Los significados de montar bicicletas cambiaron drásticamente durante la etapa más fuerte del Período Especial, y mientras montar bicicletas metonimizaba la necesidad y el dolor, también representó oportunidades para la liberación y el placer. De manera general, el acceso a otros medios de transporte influenció si la bicicleta era vista o no como liberadora. Los entrevistados conjeturan que particularmente los adultos que solo tenían acceso a taxis excesivamente costosos, un transporte público empobrecido, y caminatas extenuantes, vieron las bicicletas como algo liberador ya que facilitaban la movilidad y la consecusión de sus objetivos. Cuando hablamos del Período Especial, y más hacia adelante si fuera el caso de que continuaron montando bicicletas, los entrevistados enfatizan la facilidad con la que podían moverse ellos mismos, pasajeros y cargamento alrededor de la ciudad en uno de estos vehículos. Aprecian todas esas oportunidades y además hacen referencia a experiencias de libertad mientras se trasladaban. De manera similar, algunos entrevistados que disfrutaban de un buen acceso al transporte motorizado antes del Período Especial mencionan haber tenido dificultades para aceptar las bicicletas, pues aún guardaban la memoria de un pasado reciente en el cual moverse de un lado a otro costaba mucho menos esfuerzo. Las ásperas palabras de BR (mujer, blanca, 54 [26-31], profesional) son fulminantes. Habiendo montado [bicicleta] en su adolescencia, sus intereses se habían vuelto más sedentarios: "Nunca más volví a montar hasta que llegó el [Período Especial]. Fue un poco difícil para mí aceptar que esa era la alternativa para vivir."

En contraste con lo que sucedía en la década de 1980, los entrevistados frecuentemente afirmaron que durante el Período Especial montar bicicletas se convirtió en una actividad no sesgada por las normativas de género pues todas las personas lo hacían:

"Nunca me sentí discriminada, ni mal vista, ni siquiera vista, por montar bicicleta. En ese momento todo el mundo montaba bicicleta. . Tenerla y

Revista Zona Franca- Centro de estudios interdisciplinario sobre las mujeres (CEIM)- Maestría poder y sociedad desde la problemática de género (MG), Rosario, Argentina. ISSN, 2545-6504 http://zonafranca.unr.edu.ar/index.php/ZonaFrancal Número 29 (2021). 
montar era una bendición, sino ¿como me iba a mover? [ . . ] Tampoco pensé en cómo me veía en la bicicleta, ni en qué ropa ponerme para eso. Era una necesidad, sencillamente. AC - mujer, blanca, bisexual, 54 [2631], profesional.

Esta afirmación, que enfatiza cómo el acto de montar bicicleta expresaba las tribulaciones del período, igual resalta en qué modo la actividad -desarrollada en un ambiente de privaciones- resultaba mucho más destacada o digna de apreciación que la apariencia externa de quienes estaban al pedal, hombres o mujeres. De hecho, la entrevistada dice explicitamente -en múltiples ocasiones durante la entrevista- que durante el principio de los 90' no sintió estar sujeta a miradas (por parte de los hombres) ni a intentos de interacción mientras montaba en su bicicleta. Las duras y generalizadas circunstancias que se vivían obviaban esos juicios sociales hacia las mujeres, expandiendo de facto su libertad de movimiento y su experiencia subjetiva sobre ese movimiento.

El cambio en el significado social de las bicicletas es uno de tantos cambios acaecidos en la etapa más austera del Período Especial, que causó estrés, sufrimiento y descontento, al tiempo que ofreció oportunidades y engendró nuevas experiencias de vida. Investigaciones como el ahora clásico trabajo de la socióloga Charlotte Bloch han demostrado que la repetición de acciones y actividades físicas comunes incrementa el autorreconocimiento del cuerpo del individuo. Bloch explora cómo las nuevas experiencias de las mujeres tanto de cambios radicales en su vida como del deporte engendran en ellas nuevas experiencias de la relación entre lo que ella denomina "el yo interior y exterior." Tales actividades físicas logran llamar la atención de los actores hacia la conexión que existe entre su yo interior y exterior. Desvía la atención de la relación entre su actividad física y su visión imaginada de su cuerpo en movimiento (1987). Los intensos y generalizados cambios sociales y de la vida diaria causados por el Período Especial hicieron obsoletas varias acciones repetitivas y autoestables mientras otras acciones (ej: montar bicicletas) al

Revista Zona Franca- Centro de estudios interdisciplinario sobre las mujeres (CEIM)- Maestría poder y sociedad desde la problemática de género (MG), Rosario, Argentina. ISSN, 2545-6504 http://zonafranca.unr.edu.ar/index.php/ZonaFranca| Número 29 (2021). 
menos por un tiempo se volvieron repetitivas. En esta situación, polemizo, que montar bicicletas en algunas ocasiones engendró una apreciación entre pedalistas femeninas tanto por la actividad atlética como por el cuerpo como medio más que por el cuerpo como objeto (Young, 1990). Consideremos el testimonio de BR, quien había estado trabajando como modelo durante esa etapa:

\begin{abstract}
"Nunca sentí nada [de discriminación]. En aquellos momentos una no se fijaba en esas cosas... Yo venía del modelaje, y una imagen (la de modelo) no tenía mucho que ver con la otra (la de ciclista), en la Cuba de aquellos años. Era un poco raro para mí pensarme en una bicicleta al principio, pero fue algo que pronto superé, y que tenía que ver solo conmigo, no con la manera como me miraban los otros. Sobre todo porque yo montaba por necesidad, para solucionar un problema de mi familia. En aquel contexto, fue una decisión difícil, pero yo creo que acertada. Si me pongo a pensar, me siento más completa por haber decidido montar en aquel momento, aunque ahora tenga muchas reservas con montar. Creo que para todas las mujeres en el Período Especial fue parecida la experiencia. Conozco varias mujeres que tuvieron que vencer sus miedos a montar. Para algunas en algún momento llegó a ser divertido, y todavía montan, pero para muchas otras fue una decisión por el contexto."
\end{abstract}

El recuerdo de BR es especialmente impactante dado su forma de articular el cambio que sufrió en el tránsito desde el verse a sí misma como modelo hasta el cómo experimentaba el momento de montar bicicleta. Ella entiende la experiencia como una motivación interior, que trata de sopreponerse a retos (físicos), y precisamente no de una objetificación por ella misma u otros. BR también se refiere a su experiencia como común. Su testimonio y el de otras expresan cambios en la autopercepción basada en desempeño físico y experiencia más que en apariencia física. Estos cambios ocurrieron a pesar de dolorosos retos - de hecho, ocurrieron en parte precisamente gracias a sobreponerse a esos retos.

Revista Zona Franca- Centro de estudios interdisciplinario sobre las mujeres (CEIM)- Maestría poder y sociedad desde la problemática de género (MG), Rosario, Argentina. ISSN, 2545-6504 http://zonafranca.unr.edu.ar/index.php/ZonaFranca| Número 29 (2021). 
Las entrevistadas que eran adultas durante el Período Especial como BR se sintieron llevadas a las bicicletas por las presiones para "resolver" sus problemas y los de aquellos que dependían de ellas. Montaban bicicleta como una actividad que estaba moldeada de forma primordial por un objetivo más que por la visibilidad de sus cuerpos. Estas mujeres también mencionan que montaban bicicletas más regularmente cuando se encontraban en circunstancias que requerían de ellas más "músculo", por ejemplo, cuando no había hombres disponibles para hacer el viaje. A través de esta actividad repetida, tenían oportunidades de experimentar el placer liberador de moverse capaz, atlética y activamente en el paisaje urbano.

A la misma vez, las percepciones de peligro que estaban notablemente moldeadas por la edad y el género influenciaban la experiencia de montar en bicicleta. Los retos impuestos a la movilidad en el Período Especial fueron más allá de aquellos que experimentaba el ciclista urbano promedio en el Norte Global: calles en muy mal estado; choferes y ciclistas "indisciplinados"; mucha inexperiencia al montar bicicleta; vehículos defectuosos; gomas, tubos, y otras partes que se gastaban rápidamente en el sol y el aire costero; y la falta de una iluminación buena y estable tanto en las calles como en las propias bicicletas, todo esto significaba un peligro o una percepción de ese peligro significativos. Varios entrevistados conocieron personas que sufrieron accidentes fatales y hablaban también de robos que involucraban a las bicicletas. Más allá de esos retos, algunos de los interlocutores masculinos que durante el Período Especial eran adolescentes y cuyos otros medios de transporte eran los autobuses o las caminatas se refirieron a montar bicicletas como una experiencia liberadora. De hecho, el cubano director de nuestro documental Rodando en La Habana: Bicycle Stories recuerda el acto de montar bicicleta tanto como una aventura física que como una forma, relativamente segura, de acceder a lugares potencialmente peligrosos. Ninguna de las interlocutoras femeninas, que aparte de eso eran demográficamente similares [a los interlocutores masculinos], recuerda la relación entre montar bicicletas y el peligro

Revista Zona Franca- Centro de estudios interdisciplinario sobre las mujeres (CEIM)- Maestría poder y sociedad desde la problemática de género (MG), Rosario, Argentina. ISSN, 2545-6504 http://zonafranca.unr.edu.ar/index.php/ZonaFranca| Número 29 (2021). 
de esa manera. De hecho, muchas hablan de como su uso de las bicicletas fue restringido:

\begin{abstract}
"Yo empecé desde chiquitica y enseñé a mi hermana: yo con 11 años y ella con 22 (...) Esa era mi libertad. Mi primera bicicleta me la trajo mi papá; se la había encontrado en una esquina en Japón. Era roja, con una cestica negra, y yo iba con Nani, la perra, para arriba y para abajo. La gente decía: 'Mira, por ahí va la chinita de la bicicleta...' Pero hubo un tiempo en el que dejé de montar: cuando estaban matando por las bicicletas, mi mamá me la quitó. Me dijo que me la iban a pintar en el barco en el que trabajaba mi papá [era marino mercante] y nunca más me la devolvieron. Eso fue como en el 1996, ya había cumplido los 15 años. En aquella época en Santo Suárez mataban, debajo del puente de Santa Catalina y Vento: ponían un hilo, una pita, una soga, y te la levantaban y te entraban a palos. Hubo gente a la que dejaron ahí con contusión cerebral, derrame cerebral... [Porque] en aquella [época] la bicicleta era el medio para la sobrevivencia. Era un medio de transporte, pero [salir en ella] era jugártela. $Y$ encima la alimentación... Y la gente flaca. . . Yo sí recuerdo que eran más los hombres que montaban la bicicleta..." SMGN - mujer, blanca, heterosexual, 38 [10-15], profesional.
\end{abstract}

Si bien esas intervenciones de los padres no ocurrían en términos explícitamente sesgados por el género, sólo las mujeres las mencionaron. Como demuestra la cita previa, los peligros eran múltiples y -- al menos en leyenda urbana -- en algunos casos hasta extremos. Al mismo tiempo, nuestra investigación no fue capaz de determinar la frecuencia de o la influencia del género en los peligros. Varios entrevistados mencionaron que, siempre que era posible, los hombres optaban por montar las bicicletas en lugar de las mujeres en su círculo, aparentemente para proteger a esas mujeres. A medida que las condiciones materiales se volvieron menos complejas, la remasculinización de las bicicletas emergió como parte de la reinstauración de los paradigmas tradicionales bajo los

Revista Zona Franca- Centro de estudios interdisciplinario sobre las mujeres (CEIM)- Maestría poder y sociedad desde la problemática de género (MG), Rosario, Argentina. ISSN, 2545-6504 http://zonafranca.unr.edu.ar/index.php/ZonaFrancal Número 29 (2021). 
cuales son los hombres los que desempeñan las actividades que son consideradas más físicamente demandantes.

De manera interesante, ningún entrevistado habló sobre violencial sexual, tanto física como verbal, como un peligro durante el Período Especial, sino que se concentraron más en asaltos y robos. Es cierto que no se puede negar la posibilidad de que las entrevistadas no querían hablar sobre este tópico cargado. $Y$, si bien esa violencia sexual puede haber ocurrido, se puede interpretar que no fue recordada como un peligro de peso. Si los pedalistas fueron asaltados independientemente del género, esta norma reafirma mi argumento de que, durante la etapa más fuerte del Período Especial, de forma general las mujeres no fueron juzgadas socialmente por montar bicicletas. También reafirmaría la primera parte de mi argumento, de que las demandas de aquellos tiempos abrieron oportunidades para que las mujeres practicaran la fuerte actividad física de montar bicicletas en términos más equitativos con los hombres que en períodos de tiempo previos al Período Especial, y que muchas de ellas encontraron esta práctica empoderadora y liberadora.

A pesar de que previo al Período Especial las mujeres que montaban bicicletas no eran consideradas femeninas o sexys, algunas fuentes indican que -al tiempo que la mayor parte de la población urbana comenzó a montar- dicha actividad comenzó a presentar visos sensuales. VF - hombre, negro, heterosexual, 59 [3136], profesional - escribe: "cuando llevaba una muchacha especial en la parrilla, estábamos conectados, íbamos por caminos muy solitarios, mis manos se extendían hacia atrás para tocar/rozar sus . . . muslos. Claro que eso es algo que sólo haces cuando estás en una relación muy íntima... cómplice. Lo interesante es que en la bicicleta son posibles esos contactos, esos acercamientos." Mientras las locaciones solitarias también hablan de peligros potenciales, recuerdos como estos articulan las sensualidades de la proximidad en actividades físicas. No obstante, es importante como este ejemplo describe un modelo de normativo de sensualidad más orientado al género con el hombre como actor y la mujer como cómplice. Ella no aporta significativamente a la movilidad, pero en cambio la sensualiza, para el

Revista Zona Franca- Centro de estudios interdisciplinario sobre las mujeres (CEIM)- Maestría poder y sociedad desde la problemática de género (MG), Rosario, Argentina. ISSN, 2545-6504 http://zonafranca.unr.edu.ar/index.php/ZonaFranca| Número 29 (2021). 
hombre y quizá para ella misma también. La siguiente cita también sugiere que para el hombre esta sensualidad involucraba ejercer su estatus de género a través de la actividad física de llevar a una parrillera:

"A mi esposo le encantaban las bicicletas con parrilla, para estar montando a las mujeres. A él le encantaba que yo me montara en la parrilla, así todo el mundo veía que él me llevaba, que él podía conmigo, que él era el hombre de la casa." CA - mujer, blanca, 60 [32-37], profesional.

Nada, película de 2001 de Juan Carlos Cremata, ambientada en Cuba durante el Período Especial, sensualiza el montar en bicicleta a través de la relación de dos jóvenes trabajadores postales. Su amistad, su cortejo y su romance se desarrollan sobre y en la bicicleta de Carlos. Estampando cartas en la oficina postal, Carla observa con anhelo al repartidor mientras él se embarca en sus viajes. Varias escenas los muestran en conversaciones, caminando juntos con la bicicleta a su lado, o a Carlos montando y llevando a Carla entubada. Los comienzos de su intimidad física no están representados precisamente con piel, sudor y sábanas. En cambio, en una secuencia lírica, ligera y desenfadada en la cual Carlos lleva a Carla en la parrilla por el enorme tazón de la Fuente Luminosa, ambos caen juntos de la bicicleta en el agua, se ríen mientras pelean en ella, y se besan mientras la cámara los rodea con un plano de 360 grados. Si bien Carla no pedalea la bicicleta de Carlos por sí sola, se siente cómoda con y en ella. Sus atuendos prácticos no impiden sus movimientos y los nombres y estaturas similares del par hacen implícitas su capacidad física y su paridad con respecto a Carlos.

En Nada, ese montar bicicleta que está sensualmente energizado, también trabaja de otras maneras en contra de dogmatismos y regulaciones paralizantes. Mientras en la mayoría de los textos cubanos del período, montar bicicletas era visto como una actividad revolucionaria que salvaría a Cuba en los términos oficialmente definidos, en Nada montar bicicleta es un medio gracias al cual los ciudadanos individuales alcanzan sus metas, metas que son revolucionarias en sus propios

Revista Zona Franca- Centro de estudios interdisciplinario sobre las mujeres (CEIM)- Maestría poder y sociedad desde la problemática de género (MG), Rosario, Argentina. ISSN, 2545-6504 http://zonafranca.unr.edu.ar/index.php/ZonaFranca| Número 29 (2021). 
términos. El proyecto impulsivo e ilegal de Carla de reescribir cartas lleva alegría a los destinatarios, refuerza relaciones interpersonales, y rompe impases emocionales. Esas cartas que Carla cura y Carlos reparte conectan a las personas alrededor de la ciudad y el mundo. Cuando comienza a sospecharse de sus actividades, un consternado e inventivo Carlos evade hábilmente (montado en su bicicleta) al jefe colérico y hambriento de poder (que monta en un automóvil) en una persecución de policía y ladrones, y logra esconder la evidencia. Su carrera en bicicleta expresa e incrementa la participación individual de quienes con sus energiás eróticas y amorosas tienen el potencial de cambiar, y por lo tanto salvar, a Cuba.

Para el realizador Cremata la bicicleta es un emblema del Período Especial. No obstante, él también acota que estuvo mucho tiempo fuera del país en los 90'con su filme Viva Cuba! y que sus ingresos en el extranjero mejoraron su estilo de vida. Cremata atribuye su representación de las bicicletas en Nada a esas experiencias particulares y bastante únicas. Durante ese tiempo en Cuba, frecuentemente observaba el ciclismo urbano y apreció su estética, pero no tuvo que montar él mismo por necesidad (Cremata, 2016). Su alegre presentación lírica articula los sensuales placeres de montar en bicicleta a través de las penalidades del período.

Las sensualidades de la cultura de la bicicleta también aparecen en el volumen Cubabici. Estos dibujos humorísticos entresacados de los periódicos cubanos, presentan parejas compartiendo una bicicleta, pedaleando juntos, fllirteando y teniendo sexo durante sus excursiones, y a figuras femeninas con pronunciadas curvas bicicleteando y sentadas en la parrilla. El dibujante De la Nuez reunió a hombres cubriendo las parrillas de las bicicletas con suaves cojines para atraer mujeres vestidas y actuando provocativamente para aumentar sus posibilidades de obtener un empujón (2016).

Revista Zona Franca- Centro de estudios interdisciplinario sobre las mujeres (CEIM)- Maestría poder y sociedad desde la problemática de género (MG), Rosario, Argentina. ISSN, 2545-6504 http://zonafranca.unr.edu.ar/index.php/ZonaFranca| Número 29 (2021). 
Sus historias le hablan a una cultura de sensualidad y sexualidad imaginada y desarrollada alrededor de la bicicleta. Los personajes femeninos de los dibujos humorísticos de Nuez son un variado conjunto que incluye conductores y "parrilleras" sexualizados, no sexualizados, y figuras que viajan solitarias, en pareja y en familia, y que realizan todo tipo de tareas. Esta plétora de representaciones habla de cómo la actividad física de andar en bicicleta que incorporó sensualidad y sexualidad también incorporó a las mujeres como intérpretes de esa actividad.

La información en los periódicos buscaba desactivar la noción de la bicicleta como indicador de subdesarrollo; una de estas estrategias fue representarla como algo erótico. Por ejemplo, un artículo publicado el día de San Valentín que describe el uso generalizado de la bicicleta en los Países Bajos termina con esta frase: "Montar bicicletas es la forma más romántica y económica de superar cualquier crisis de locomoción" (Riveros Olavarría, 1990). Un texto del periodista Manuel Enriquez Lagarde, aparecido en el diario Juventud Rebelde, combina una descripción de los beneficios de andar en bicicleta y los planes para mejorar el transporte urbano en La Habana con reflexiones sobre los placeres de montar a su novia en la bicicleta. Los artículos en las fuentes de noticias cubanas también destacan los beneficios de andar en bicicleta para toda la población, las formas en que se pueden mejorar las prácticas de andar en bicicleta y los placeres de andar en bicicleta para hombres y mujeres. Esto es proyectado como una actividad positiva, placentera y revolucionaria, características que el documental Forever (1994) de Luis Orlando Deulofeu también articula con ironía. Estas imágenes de los medios de comunicación destinadas a fomentar el uso de este vehículo también facilitaron el número de mujeres bicicleteras al representar la actividad como algo apropiado para las mujeres y a las mujeres como atractivas mientras pedaleaban.

Los textos culturales y las contribuciones de los interlocutores aquí analizados indican que al menos algunas mujeres encontraron el bicicleteo como algo liberador, a pesar de los desafíos que trajo. IR, mujer, blanca, heterosexual, de alrededor de

Revista Zona Franca- Centro de estudios interdisciplinario sobre las mujeres (CEIM)- Maestría poder y sociedad desde la problemática de género (MG), Rosario, Argentina. ISSN, 2545-6504 http://zonafranca.unr.edu.ar/index.php/ZonaFranca| Número 29 (2021). 
55 años [alrededor de 27], cuentapropista, es una de las muchas cuyas palabras expresan el fenómeno.

"Montar bicicleta es riquísimo, me hacía sentir maravillosamente bien. Yo aprendí cuando mi hija mayor (nacida en el 1991) tenía siete meses... Y le cogí el gusto, yo no soltaba la bicicleta. Era también mi formar de hacer ejercicio, des despejar... Y me sentía independiente, libre."

A medida que las presiones del Período Especial fueron disminuyendo, aumentó el transporte motorizado y las subvenciones gubernamentales para el ciclismo se redujeron. La Habana ha visto cambios en la tocante a la cultura de la bicicleta. De nuevo, se ha vuelto convertido menos normativo que las mujeres anden en bicicleta y sus experiencias son moldeadas en consecuencia. Primero, a pesar de una subcultura de corta duración, propia del Período Especial, que consideraba sexy a las mujeres en bicicleta vistiendo tejidos de lycra, nuestros interlocutores en general estuvieron de acuerdo en que hoy, nuevamente, las ciclistas femeninas deben renunciar alguna parte de su feminidad porque generalmente no usan estilos que expresen la feminidad normativa al montar en bicicleta. Aunque existe una pequeña cultura internacional de clase alta sobre mujeres que visten ropa deportiva como moda femenina, los desarrollos comerciales -que en Norteamérica han propiciado la expansión de una estética femenina de ajustada ropa deportiva para clases privilegiadas- están mucho menos extendidos en Cuba. De manera adicional, puesto que el look de la lycra no está bien aceptado en el mundo profesional o fuera de la informalidad del barrio de clase trabajadora, para encajar, una bicicletera necesitaría cambiarse de ropa al llegar a su destino.

Las nociones de modestia son otra forma relacionada en la que es articulada la incomodidad en torno a la expresión de roles sexuales mientras se monta en bicicleta. Varios entrevistados hablaron sobre lo inapropiado de vestir falda al pedalear hoy en día, al menos sin llevar pantalones cortos debajo. ALI, mujer, mestiza, 30 [2-7], profesional, informa que la combinación entre una falda y una

Revista Zona Franca- Centro de estudios interdisciplinario sobre las mujeres (CEIM)- Maestría poder y sociedad desde la problemática de género (MG), Rosario, Argentina. ISSN, 2545-6504 http://zonafranca.unr.edu.ar/index.php/ZonaFranca| Número 29 (2021). 
bicicleta china marca Forever que la identificó como cubana la expuso a todo tipo de comentarios sexuales no deseados por parte de los hombres. Muchas interlocutoras se consideran obligadas a elegir entre asumir una feminidad más "masculina" para andar en bicicleta de un modo socialmente aceptable o mantener una feminidad más "femenina" en su apariencia y comportamiento y no andar en bicicleta. Incluso las mujeres que montan como parrilleras tienen la sensación de ser consideradas indecentes según su ropa y la forma en que se sientan y se aferran a la persona que pedalea.

Después del austero Período Especial, las habaneras en bicicleta tienden una vez más a ser juzgadas de acuerdo con modelos normativos de género, y sus acciones no son vistas como medios normativos para lograr los fines deseados. Pueden ser considerados "héroes" debido a los peligros percibidos en relación con el pedaleo. Al mismo tiempo, e irónicamente, es considerado que lo más aceptable para ellas es ceder el control de su destino callejero a un ciclista, depositando en él toda la cofianza y montando como parrilleras. Una entrevistada -que elige pedalear ella misma- informa una variedad de sanciones verbales por parte de los espectadores, incluidos comentarios que piden: "deja de torturarla", cuando es ella quien lleva un parrillero masculino. A pesar de tal reprobación, varios entrevistados continúan usando la bicicleta y prefieren pedalear. Una cita el deseo de tener el control de su propia seguridad; otra el poder controlar la bicicleta que posee, presuntamente por su valor.

En este contexto cambiante, las mujeres experimentan y enfrentan el control a través del acoso y la violencia sexual verbal y física. Considérese esta pregunta y su respuesta:

"¿Alguna vez te sentiste o te has sentido discriminada por montar bicicleta? Para nada. No, al contrario. Lo que sí había era piropos, que la gente se mete contigo... Lo que pasa es que los hombres agresivos de aquí... Lo mismo te dicen que se te marca... [la vagina] en el asiento... O de ir en camiseta y sentir que con un poco más cae adentro de mis senos. Pero

Revista Zona Franca- Centro de estudios interdisciplinario sobre las mujeres (CEIM)- Maestría poder y sociedad desde la problemática de género (MG), Rosario, Argentina. ISSN, 2545-6504 http://zonafranca.unr.edu.ar/index.php/ZonaFranca| Número 29 (2021). 
bueno, yo voy con mis audífonos y si me dicen una barbaridad, yo me hago la que no lo escuché. CA, blanca, mujer, heterosexual, 60 [32-37], profesional."

Aunque al principio esta entrevistada responde que se siente tratada por igual, como mujer, cuando circula en bicicleta, después de una reflexión más profunda, descubre que está sujeta a miradas objetivantes y acercamientos de carácter sexual no solicitados. Ella usa el término barbaridad. La cultura del piropo, una cultura de coqueteo agresivo, es un lugar común en La Habana y genera mucho debate. Algunas lo consideran incómodo en tanto otras dicen que, cuando no lo experimentan, se sienten invisibles. Uno de los entrevistados sugiere que todas las mujeres experimentan este coqueteo cuando están en público independientemente de si andan en bicicleta o no. La mayoría de los entrevistados cree que este tipo de contacto es mucho más pronunciado cuando se anda en bicicleta, quizás, sugiero, porque la mujer es interpretada como más expuesta físicamente y por estar realizando una actividad del género opuesto. La prevalencia de la cultura piropo puede explicar por qué el entrevistado citado anteriormente de entrada no reconoce como tal el acoso, sino que ha desarrollado una estrategia de mitigación a través del no compromiso: negándose a desempeñar el papel de audiencia atenta. Las entrevistadas afirman que las mujeres que en estos días circulan en bicicleta de nuevo tienden a ser etiquetadas como marimacho, pese a lo cual esta entrevistada continúa viajando en este medio de transporte.

Aunque la Revolución en Cuba condujo, como en otras naciones socialistas, a una valorización física de los cuerpos de las mujeres como cuerpos de trabajo, la vieja cultura latina -de diferenciación de la género y feminización de las mujeresnunca desapareció en Cuba y ha resurgido con el desarrollo creciente de las estructuras capitalistas. Es bien sabido que las mujeres que practican actividades no normativas según género a menudo son vigiladas (generalmente por hombres)

Revista Zona Franca- Centro de estudios interdisciplinario sobre las mujeres (CEIM)- Maestría poder y sociedad desde la problemática de género (MG), Rosario, Argentina. ISSN, 2545-6504 http://zonafranca.unr.edu.ar/index.php/ZonaFrancal Número 29 (2021). 
a través de insinuaciones sexuales no deseadas y violencia sexual, y Cabrera y mis interlocutores informan haber experimentado tal censura en la Habana de hoy.

\section{Conclusión: ¿Andar en bicicleta por elección en La Habana?}

Al mismo tiempo, otra cohorte de ciclistas, tal vez creciente, con la que he hablado largamente en numerosas ocasiones, merece más investigación. Estos miembros, de la generación posterior al Período Especial, informan que viajan por placer y para facilitar el movimiento en la ciudad. Para muchos de ellos, la bicicleta está mucho menos conectada con el sufrimiento del Período Especial puesto que vivieron ese tiempo sobre todo, o únicamente, a través de historias. Algunos miembros más jóvenes de la creciente clase alta de La Habana, en particular, andan en bicicleta más que nada por motivos de recreación y práctica de deporte. En caso de emplear este vehículo como medio de transporte, lo estarían haciendo por verdadera elección, ya que su presupuesto les permite lo mismo ir en taxis colectivos que alquilar alguno sólo para ellos. Este grupo demográfico más joven también está influenciado por los paseos en bicicleta que algunos han experimentado estando en el extranjero y por la observación de visitantes foráneos que se mueven en tales transportes a medida que este tipo de turismo se expande por La Habana (Maëva, 2018). Andar en bicicleta puede ser una forma de emular a la parte acomodada de la población y/o a los extranjeros. Estas influencias tienden a normalizar y a elevar el estatus del ciclismo para hombres y mujeres. Una amiga cubana -que disfrutó mucho de andar en bicicleta en el Período Especial, cuando la infraestructura para bicicletas le permitía hacerlo de manera económica, segura y fácil en el barrio de Playa- se preguntó en voz alta por qué los turistas, que tienen los medios para elegir su transporte, eligen la bicicleta. Nuestras reflexiones posteriores sobre el tema incluyeron conclusiones que a menudo se escuchan en los círculos de activistas de bicicletas: placer en una actividad física ligeramente aventurera, involucrarse con el entorno urbano más de cerca de lo que sería posible

Revista Zona Franca- Centro de estudios interdisciplinario sobre las mujeres (CEIM)- Maestría poder y sociedad desde la problemática de género (MG), Rosario, Argentina. ISSN, 2545-6504 http://zonafranca.unr.edu.ar/index.php/ZonaFranca| Número 29 (2021).

Página 399 
en caso de ir en vehículos motorizados y oportunidad de sostener contactos en un área geográfica mayor de lo que sería posible en caso de andar a pie.

En 2013, el gobierno cubano publicó un documento en el que prometía apoyo para la bicicleta, como proporcionar piezas a precio de costo para mejorar el transporte urbano (De La Cantera y Figueredo, 2017). Se han observado pocos resultados concretos hasta que en noviembre de 2018 se lanzó $\mathrm{Ha}$ 'BiCi, que se anuncia como el primer proyecto de bicicleta pública en la capital (Caraballoso, 2018). [Nota de actualización: En mayo 2021, en conjunto con la Estrategia de Movilidad Ciclística, la Dirección General de Transporte Provincial La Habana (DGTPH), y el Centro de Investigación y Manejo Ambiental del Transporte, Ha'Bici abrió un segundo proyecto piloto del plan Neomovilidad: un sistema de bicicletas públicas en la zona no céntrica de Fontanar-Reparto Abel Santamaría-Wajay-CujaeReloj Club (Sánchez, 2021)]. Vélo Cuba, una pequeña empresa sin fines de lucro, es quien opera $\mathrm{Ha} \mathrm{BiCi}^{\mathrm{B}}$, trabajo que realiza con el apoyo de la Oficina del Historiador de la Ciudad. Vélo Cuba es dirigida por mujeres y promueve el ciclismo a través de proyectos como reparaciones y capacitación de conductores; para ello emplea más de cincuenta bicicletas importadas y piezas de repuesto donadas desde el extranjero. Las discusiones que he sostenido durante los últimos cinco años con los dedicados e incansablemente optimistas colaboradores de Vélo Cuba, más recientemente en diciembre de 2019, sugieren que el proyecto está verdaderamente empeñado en proporcionar bicicletas para el uso de los residentes de la ciudad, pero me dejaron curiosa acerca de la sostenibilidad, considerando que los precios son altos para muchos cubanos y, sin embargo, los ingresos de Vélo Cuba no cubren los costos a largo plazo sin las continuas donaciones. Mientras tanto, los usuarios más obvios son los turistas que llenan La Habana Vieja, donde el programa tiene su base. Los estudios realizados con poblaciones económicamente desfavorecidas en América del Norte sugieren que los programas de alquiler y préstamo de bicicletas tienden a satisfacer de forma inadecuada las necesidades

Revista Zona Franca- Centro de estudios interdisciplinario sobre las mujeres (CEIM)- Maestría poder y sociedad desde la problemática de género (MG), Rosario, Argentina. ISSN, 2545-6504 http://zonafranca.unr.edu.ar/index.php/ZonaFranca| Número 29 (2021). 
de los grupos demográficos pobres (Hoffmann, 2016). Queda por ver si Cuba es diferente.

Desde noviembre de 2017, el endurecimiento del embargo después del período presidencial de Obama ha provocado una mayor tensión en el sistema de transporte. En fecha más reciente, y más de un año después de haber completado la mayor parte de este análisis, nuevas restricciones al embargo y la pandemia de COVID-19, detectada en Cuba a principios de marzo de 2020, han significado un aumento de la escasez generalizada y el cese temporal del transporte público. Dos respuestas a nivel individual ilustran la creciente división entre los que tienen y los que tienen menos. Una es la proliferación de patinetas eléctricos y algunas bicicletas eléctricas y bicicletas compradas e importadas del extranjero; convenientemente para estos propietarios de scooters y bicicletas eléctricas, la electricidad está subvencionada por el Estado. La otra, es la resurrección de esas pocas bicicletas que han ido acumulando polvo. Los precios en los clasificados de Revolico se están disparando y las piezas de repuesto siguen siendo un problema. [Nota de actualización: En enero de 2021, la fábrica Ciclos Minerva en Villa Clara entrega más de 6,000 mil bicicletas eléctricas, destinadas -de forma prioritaria- a estudiantes y trabajadores de la Universidad de las Villas. Financiada por el presupuesto del Estado, la iniciativa surgió del Ministerio de Transporte "como alternativa ante la escasez de combustible, que limita el transporte público en el país." (CubaDebate, 2021)].

¿A dónde nos conduce el futuro? En mi opinión, las prácticas de casi tres décadas -que todavía continúan hoy-, en cuanto al uso no-recreacional de la bicicleta, ofrecen a La Habana una fecunda base para de nuevo expandir el uso del tránsito no motorizado. Estas políticas favorables a la bicicleta podrían sintonizar con proyectos visionarios desplegados en ciudades de Latinoamérica, América del Norte y, en general, del mundo entero. Se puede predecir que tales políticas serán confrontadas por voces de la comunidad de exiliados cubanos que lamentarían el regreso masivo a la bicicleta como evidencia del fracaso gubernamental y el

Revista Zona Franca- Centro de estudios interdisciplinario sobre las mujeres (CEIM)- Maestría poder y sociedad desde la problemática de género (MG), Rosario, Argentina. ISSN, 2545-6504 http://zonafranca.unr.edu.ar/index.php/ZonaFranca| Número 29 (2021). 
maltrato de la población (Hosek, 2018). Hasta hace muy poco, el gobierno cubano justificaba su relativa inacción en parte insistiendo en que los cubanos odian las bicicletas debido al legado del Período Especial. ${ }^{\mathrm{VI}} \mathrm{Si}$ bien indudablemente muchos residentes prefieren el transporte motorizado, mi investigación muestra que una cultura a favor del uso de bicicletas creció durante el Período Especial -a pesar de todo los dolores del momento- y que tal cultura continúa hoy a través de diferentes permutaciones. Ello sugiere que estas experiencias podrían aprovecharse para promover el uso de la bicicleta en la capital, tanto entre las mujeres como entre los hombres (Blanco y Moudon, 2017).

La particular historia revolucionaria del uso de la bicleta en Cuba se identifica con la historia global del ciclismo como práctica liberadora. Hoy en día, en el Norte global del continente americano, el ciclismo urbano sigue siendo en gran parte subalterno, incluso cuando es el transporte preferido por antihéroes principalmente jóvenes, masculinos e inconformistas. Las mujeres que expresan su independencia montando en bicicleta, corren el riesgo de quedar atrapadas en la mirada masculina cuando "ponen la diversión entre las piernas", como dice el eslogan del activismo de la bicicleta. Recuperar esa "cultura de la necesidad" asociada al uso de la bicicleta -de amplia base en el país durante el austero Período Especial- como una "cultura de la elección", beneficiaría a las comunidades urbanas de La Habana, podría reavivar la emancipación física femenina como capacidad en lugar de objeto, y funcionaría como modelo para los espacios urbanos a nivel mundial.

Quisiera agradecer muy especialmente a algunos de los cubanos que anduvieron en bicicleta tan poco o tanto como les fue posible durante el Período

${ }^{V I}$ Lecciones tomado de mi participación en el Té de Intercambio "Sobre uso de la bicicleta en La Habana". Palacio de Segundo Cabo, La Habana Vieja. 21 diciembre, 2017. Los Tés de Intercambio son encuentros habituales con el público organizado por la Oficina del Historiador de La Ciudad de La Habana, la entidad encargada de restauración de La Habana Vieja entre otros barrios del capital.

Revista Zona Franca- Centro de estudios interdisciplinario sobre las mujeres (CEIM)- Maestría poder y sociedad desde la problemática de género (MG), Rosario, Argentina. ISSN, 2545-6504 http://zonafranca.unr.edu.ar/index.php/ZonaFranca| Número 29 (2021). 
Especial y que se tomaron el tiempo para hablar conmigo sobre sus experiencias a través de correo electrónico, VolP y teléfono en la primavera de 2018: Violeta Cardoso, Sander Zequeira García, Isabel Pacheco, Grisel García Pérez, Vivian Rocaberto, Lourdes Suarez y Victor Fowler. Gracias también a una innumerable plétora de ciclistas y activistas de la bicicleta habaneros por la larga duración de su apoyo y amistad. Gracias a las profesoras Samantha King y Mary Louis Adams, igualmente los lectores expertos y concienzudos. Además, a Laurel Larsen, Ray Cannon, y J. Pratt.

\section{Bibliografía}

BASTIAN, Hope (2018). Everyday Adjustments in Havana: Economic Reforms, Mobility, and Emerging Inequalities. London: Lexington Books.

BENNETT, Tony, GROSSBERG, Lawrence y MORRIS, Meaghan (2005) (Editores.), New Key Words: A Revised Vocabulary of Culture and Society. London: Blackwell.

BLANCO, Hilda y MOUDON, Anne Vernez (2017). "Havana's Transportation System: Future Scenarios." Transportation Research Procedia 25: 4679-91.

BLOCH, Charlotte (1987). "Everyday Life, Sensuality and Body Culture", Women's Studies International Forum 10, no. 4: 433-42.

BLUE, Elly (2016). Bikenomics: How Bicycling Can Save the Economy. Portland, OR: Microcosm.

BOBES, Velia Cecilia (2011). "Visits to a Non-Place: Havana and Its Representation(s)", En Anke Birkenmaier y Esther Whitfield (Editoras), Havana Beyond the Ruins: Cultural Mappings after 1989. Durham, NC: Duke University Press. pp. 15-30.

BÖHM, Steffen, JONES, Campbell, LAND, Chris y PATERSON, Matthew (2007). Against Automobility. Portland, OR: Book News.

CABRERA ARÚS, María y SUQUET, Mirta (2019). "La moda en la literatura cubana, 1960-1979: Tejiendo y destejiendo al hombre nuevo", Cuban Studies 47: 195-221.

Revista Zona Franca- Centro de estudios interdisciplinario sobre las mujeres (CEIM)- Maestría poder y sociedad desde la problemática de género (MG), Rosario, Argentina. ISSN, 2545-6504 http://zonafranca.unr.edu.ar/index.php/ZonaFranca| Número 29 (2021). 
CALVO-PEÑA, Beatriz (2005). "Prensa, política y prostitución en la Habana finisecular: El caso de la cebolla y la 'Polemica de las meretrices'”, Cuban Studies 36: 23-49.

CARABALLOSA, Eric (2018). "Ha'Bici: en bicicletas públicas por La Habana: Desde este 24 de noviembre funciona un proyecto piloto en el Centro Histórico de La Habana", OnCuba News, 10 de noviembre, 28. https://oncubanews.com/cuba/habici-en-bicicletas-publicas-por-la-habana/.

CHANAN, Michael (2017). "Then Came the Special Period: Cinema of Fernando Pérez" en Guy Baron, Ann Marie Stock y Antonio Álvarez Pitaluga (Editores), The Cinema of Cuba: Contemporary Film and the Legacy of Revolution. London: I. B. Tauris. pp. 133-46.

CREMATA, Juan Carlos (2016). Entrevista con Jennifer Ruth Hosek y Jaime Menéndez Santos, marzo.

CLUSTER, Dick y HERNÁNDEZ, Rafael (2006). The History of Havana. New York: Palgrave Macmillan.

CUBADEBATE (2021). "Regresan las bicicletas Minerva a las calles cubanas" 30 de mayo, http://www.escambray.cu/2021/regresan-las-bicicletas-minerva-a-lascalles-cubanas/

DE LA CANTERA, Cynthia y FIGUEREDO, Ernesto J. Gómez. “¿Por qué escasean las bicicletas en La Habana?" El Toque, 1 de septiembre. https://eltoque.com/por-que-escasean-las-bicicletas-en-la-habana/

DE LA NUEZ, René (2016). Entrevista con Jennifer Ruth Hosek y Jaime Menéndez Santos. marzo.

ESPINA, Mayra (2008). "Viejas y nuevas desigualdades en Cuba: Ambivalencias y perspectivas de la re-estratificación social", Nueva Sociedad 216 (julio-agosto): 133-49.

GUEVARA, Che (1964). "Discurso en la inauguración de la fábrica de bicicletas de Caibarién (19 July)", Revolución, 20 de julio.

GUROFF, Margaret (2016). The Mechanical Horse: How the Bicycle Reshaped American Life. Austin: University of Texas Press.

Revista Zona Franca- Centro de estudios interdisciplinario sobre las mujeres (CEIM)- Maestría poder y sociedad desde la problemática de género (MG), Rosario, Argentina. ISSN, 2545-6504 http://zonafranca.unr.edu.ar/index.php/ZonaFranca| Número 29 (2021). 
LAGARDE, Manuel Henríquez (1990). "Te llevo conmigo, Lucía", Juventud Rebelde (La Habana), 25 de noviembre, 3.

HERNÁNDEZ-REGUANT, Ariana (2009). Cuba in the Special Period: Culture and Ideology in the 1990s. New York: Palgrave Macmillan.

HOFFMANN, Melody (2016). Bike Lanes Are White Lanes: Bicycle Advocacy and Urban Planning. Lincoln, NE: University of Nebraska Press.

HOSEK, Jennifer Ruth (2018). "Beyond Big Buicks? On Havana's Tourism and Transport Cultures", charla en el Department of Geography. University of California, Berkeley. 21 de febrero.

- (2012). Sun, Sex, and Socialism: Cuba in the German Imaginary. Toronto: University of Toronto Press.

KABOUS, Magali (2009). "Encuentro con Fernando Pérez", Caravelle: Cahiers du Monde Hispanique et Luso-Brésilien 92: 189-98.

LENSKYJ, Helen (1987). "Female Sexuality and Women's Sport", Women's Studies International Forum 10, no. 4: 381-86.

LEWIS, Oscar, LEWIS, Ruth M. and RIGDON, Susan M. (2019). "The Literacy Campaign." en Barry Carr, Aviva Chomsky, Alfredo Prieto y Pamela Maria Smorkaloff (Editores), The Cuba Reader: History, Culture, Politics. Durham, NC: Duke University Press, pp. 389-94.

Maëva (2018). "Cyclists Pedalling to Make Bikes Cool Again in Cuba", The Observers, 3 de octubre. https://observers.france24.com/en/20181003-youngcubans-havana-cycling-bicycles.

MUELLNER, Beth (2002). "The Deviance of Respectability: NineteenthCentury Transport from a Woman's Perspective", Journal of Transport History 23, no. 1: 37-45.

NAROTZKY, Viviana (2002). "Our Cars in Havana", en Peter Wollen

y Joe Kerr (Editores), Autopia: Cars and Culture. London: Reaktion, pp. 16976.

PÉREZ, Louis (2001). On Becoming Cuban: Identity, Nationality, and Culture. New York: Harper.

Revista Zona Franca- Centro de estudios interdisciplinario sobre las mujeres (CEIM)- Maestría poder y sociedad desde la problemática de género (MG), Rosario, Argentina. ISSN, 2545-6504 http://zonafranca.unr.edu.ar/index.php/ZonaFranca| Número 29 (2021). 
PETSCHEK, Bruce y CHURCHHILL, C. Phred (1996). Velorution: One City's Solution to the Automobile, Cambridge, MA: 7 Generations Video.

SÁNCHEZ, Mildrey (2021). "Más de 6 mil bicicletas mecánicas para mercado en moneda nacional tras déficit de combustible", Directorio Cubano. 2 de junio. https://www.directoriocubano.info/actualidad/mas-de-6-mil-bicicletas-mecanicaspara-mercado-en-moneda-nacional-tras-deficit-de-combustible/

RíOS, Humberto Valdes (1993). "Bicycles and Tricycles in Cuba: An Alternative for Sustainable Development, the Case of the City of Havana", Conference Proceedings CODATU, Paris.

RIVEROS OLAVARRÍA, Patricia (1990). "Bicicleteando en Holanda", Juventud Rebelde (La Habana), 15 de febrero, sin página.

RUFFINELLI, Jorge (2005). Sueños de realidad Fernando Pérez: Tres decades de cine. Madrid: Fundación Autor.

SANTOS MENÉNDEZ, Jaime y HOSEK, Jennifer Ruth (2016). Rodando en La Habana: Bicycle Stories. Pancha Producciones.

SARTRE, Jean-Paul (1961). Sartre on Cuba: A First-Hand Account of the Revolution in Cuba and the Young Men Who Are Leading It-Who They Are and Where They Are Going. New York: Ballantine Books.

SCARPACI, Joseph y HALL, Annie Z. (1995). "Havana Pedals through Hard Times", Sustainable Transit, no. 5: 4-5.

SCARPACI, Joseph L., SEGRE, Roberto, COYULA, Mario y SEGRE, Roberto (2002). Havana: Two Faces of the Antillean Metropolis. Chapel Hill: University of North Carolina Press.

SUÁREZ, Karla (2019). “Tres juguetes”, Entrevista con Daniel Alarcón. Radio Ambulante. 9 de avril. https://radioambulante.org/audio/toy-story

TURNER, Graeme (2003). British Cultural Studies: An Introduction. London: Routledge.

VIVANCO, Luis A. (2013). Reconsidering the Bicycle: An Anthropological Perspective on a New (Old) Thing. New York: Routledge.

Revista Zona Franca- Centro de estudios interdisciplinario sobre las mujeres (CEIM)- Maestría poder y sociedad desde la problemática de género (MG), Rosario, Argentina. ISSN, 2545-6504 http://zonafranca.unr.edu.ar/index.php/ZonaFrancal Número 29 (2021). 
WEISS, H. Eugene (2003). Chrysler, Ford, Durant, and Sloan: Founding Giants of the American Automotive Industry. New York: McFarland.

Xianglin, Mao (2014). Sobre el socialismo en Cuba. Beijing: China Intercontinental Press.

YOUNG, Iris Marion (1990). Throwing Like a Girl and Other Essays in Feminist Philosophy. Bloomington, IN: Indiana University Press.

ZULOAGA, Martínez, José A. (2013). "El Che en Caibarién", Joomla 2.5, 7 de octubre. 